\title{
Herramientas de contabilidad de gestión para generar valor económico, ambiental y social en activos biológicos forestales. Panel de control e indicadores estratégicos en silvicultura
}

Management accounting tools to generate economic, environmental and social value of forest biological assets. Control Panel and strategic indicators in forestry

\author{
Andrés Alberto Mancini \\ Facultad de Ciencias de la Administración, \\ Universidad Nacional de Entre Ríos, \\ Argentina. \\ E-mail:manciniaa@gmail.com
}

Fecha de recepción: 04/03/2016 Fecha de aceptación: 20/06/2016
Palabras clave

- silvicultura

- objetivos

- indicadores

- gestión

- decisiones

\section{Resumen}

Un proceso de planeamiento estratégico eficiente en la actividad silvícola exige disponer de un sistema integral de información contable y de gestión, a efectos de que las decisiones gerenciales durante el ciclo biológico de las plantaciones resulten de utilidad para potenciar en forma sustentable el valor del bosque bajo la meta del triple resultado.

Al tratarse de una producción a largo plazo, con procesos continuos y terminales, se hace necesario que la capacidad de cambio que tienen los bosques cultivados sea manejada en forma objetiva por el hombre (gestión del cambio), pero también monitoreada por el control gerencial (medición del cambio).

Los objetivos del artículo son:

- Demostrar la utilidad de la información generada por la contabilidad de gestión para administrar y gestionar activos forestales,

- Exponer una metodología para el diseño de una herramienta que permita crear valor económico, social y ambiental en la gestión de bosques cultivados. 
Se propone un sistema de información integrado de datos específicos para la actividad (panel de control, objetivos e indicadores de gestión) que permita brindar información cuantitativa y cualitativa sobre la evolución del ciclo vital de las plantaciones y aspectos integrales de la marcha del negocio: financieros, comerciales, producción y tecnología, ambientales y sociales.

El éxito del proceso de planeamiento estratégico se verá reflejado al final del ciclo biológico, al incrementar y potenciar la rentabilidad de los bosques cultivados dentro de la meta de triple resultado: crear valor económico en forma sostenible, con generación de valor social y ambiental.

\begin{abstract}
A process efficient strategic planning in silviculture, requires the availability of a comprehensive system of accounting and management information, to the effect that management decisions during the life cycle of plantations, will prove useful for enhancing sustainably the value of forest, under the goal of triple result.

Being a long-term production with continuous processes and terminals, it is necessary that the capacity for change that have cultivated forests is handled objectively by man (change management), but also monitored by the management control (measuring the change).

The objectives of the article are:

- To demonstrate the usefulness of the information generated by the management accounting to administer and manage forest assets.

- Exhibit a methodology for designing a tool to create economic, social and environmental value in the management of cultivated forests.

It is proposed an information system integrated data specific to the activity (control panel, objectives and performance indicators) that allows providing quantitative and qualitative information on the evolution of the life cycle of plantations and integral aspects of running the business is proposed: finan-

cial, trade, production and technology, environmental and social.

The success of the strategic planning process, will be reflected at the end of the life cycle, to increase and enhance the profitability of cultivated within the target of triple outcome forests: creating economic value in a sustainable manner, generating social and environmental value.
\end{abstract}

Keywords

- forestry

- objectives

- indicators

- management

- decisions 


\section{Introducción}

Las etapas silviculturales de manejo, gestión, control y administración de activos biológicos forestales tienen algunas características especiales: maneja seres vivos, el bosque es bodega y fábrica a la vez, tienen lenta rotación del ciclo operativo y el retorno de inversión es a largo plazo (Mancini, 2013). Estas características condicionan el sistema de información, gestión y control ya que:

- se manejan procesos terminales y continuos,

- existe la «gestión del cambio» de los activos manejados,

- la gerencia lidera el «control del cambio»; facilita y controla las transformaciones biológicas promoviendo 0 estabilizando las condiciones (ej. humedad, fertilidad, nutrientes, luminosidad, elección de suelos, etc.) para que el proceso tenga lugar.

Las particularidades mencionadas originan que la información generada desde el segmento de contabilidad de gestión del ente tenga trascendencia y utilidad para la toma de decisiones estratégicas a to largo del ciclo vital de las plantaciones. La misma debe brindar señales de alerta para la toma de medidas correctivas en todas las dimensiones de análisis (financiera, comercial, producción y patrimonio forestal, social-ambiental y recursos humanos).

En el caso de activos biológicos forestales los efectos de valuación y revelación de su transformación biológica, así como su administración, registración, gestión, control e información contable, tienen un vector transversal a todos los segmentos contables.

En la primera parte del presente artículo se destacan conceptos generales sobre silvicultura y forestación y su alineación con los segmentos contables. La segunda parte se concentra en la contabilidad de gestión 0 gerencial, y en la utilidad de la información de control de gestión para administrar y gestionar activos forestales. En la tercera parte se desarrolla la metodología para la elaboración del plan y mapa estratégicos, panel de control e indicadores de gestión, con el objetivo final de crear valor económico, social y ambiental en silvicultura. Por último algunas conclusiones obtenidas del trabajo.

\section{El segmento de contabi- lidad de gestión y los activos biológicos forestales}

\section{Algunos conceptos básicos sobre silvicultura y forestación}

Por silvicultura se entiende el cuidado de los bosques y también, por extensión, la ciencia que trata del cultivo de los mismos (Ministerio de Economía y Servicios Públicos, Secretaría de Agricultura, Ganadería y Pesca, 1995). Se encarga de desarrollar aquellas técnicas que resultan ser las más convenientes de aplicar en las masas forestales con el objetivo de lograr una producción de bienes y de servicios para hacer frente a las necesidades y demandas de la sociedad. Los principios básicos que debe garantizar son: la continuidad a través del tiempo y uso múltiple que la producción forestal tendrá hacia el futuro.

Por otra parte, forestación representa la implantación de un bosque en una zona libre de masa boscosa (Ministerio de Economía y Servicios Públicos, Secretaría de Agricultura, Ganadería y Pesca, 1995).

La silvicultura incluye las actividades de:

- plantación, regeneración y tala de aquellos árboles de los cuales se extraen productos maderables y no maderables,

- desarrollo de nuevas especies de árboles,

- estudio en profundidad de las especies existentes,

- investigación sanitaria y ecológica.

El ciclo de vida operativo de toda plantación forestal es muy largo. Los períodos alcanzados entre el establecimiento de la misma y su cosecha, o la 
recuperación «natural» de un bosque, rara vez es inferior a 8 años (para el eucaliptus promedia los 10 años y para el pino los 15 años), aunque pueden existir manejos (raleos) a edades más tempranas con objetivos silviculturales.

\section{La necesaria segmentación contable en la temática de bosques cultivados} Los bosques cultivados son activos biológicos contables donde los efectos de la medición y revelación contable de su transformación biológica, así como su administración, registración, gestión, control e información contable, tienen un vector transversal a todos los segmentos de la teoría general contable. Esta afirmación se soporta en lo siguiente:

- su relación con el entorno que afecta a estos bienes,

- la realidad concreta que afecta a la actividad forestal como una industria particular en cuanto a sus procesos y ciclos operativos,

- la variedad de objetivos, metas, disposición y necesidades que tienen los distintos usuarios internos y externos de información contable de estos entes,

- su incidencia económica en las economías nacionales y regionales,

- su relación con el entorno social, ambiental y en la generación de empleo,

- su impacto en los ecosistemas,

- la necesaria gestión del cambio y de su transformación biológica,

- ser bienes estratégicos a nivel de políticas económicas de los Estados.

De lo mencionado se desprende la incidencia de la silvicultura en todos los segmentos contables, modelos contables y en el diseño final de los sistemas de información en cada segmento. Sin embargo, el presente artículo se concentra sólo en aspectos de importancia de los bosques cultivados en el segmento de contabilidad de gestión, así como sus reportes e indicadores principales para gestionar y medir el cambio biológico.

\section{El modelo de contabilidad de gestión en la gestión de activos forestales}

La contabilidad de gestión (empresarial o gerencial) se orienta a servir los intereses, necesidades, objetivos y metas de los usuarios internos de la organización, brindando información de base administrativa y en forma más analítica que la contabilidad financiera. Se «ocupa de medir e informar el cumplimiento de objetivos organizacionales» (García Casella, 2000). Este segmento tiene una relación directa con la administración, ya que elabora para la misma información contable y otros informes de gestión (Soto, 2011). Se caracteriza por:

- dejar de lado la partida doble como único método de registración para interpretar los hechos económicos. La igualdad contable patrimonial por sí sola no es fundamental y única para entender hechos económicos,

- generar información para usuarios de varios sectores de la sociedad (contables, operativos, ingenieros, gerentes, comerciales, personal de capital humano, directores, auditores, etc.),

- utilizar nuevas fórmulas de cálculo e indicadores aceptados y definidos por la comunidad 0 por el mismo ente,

- utilizar unidades de medidas para los indicadores e informes en términos monetarios, no monetarios y descriptivos,

- ampliar el espectro de los conceptos referidos a unidad de medida, capital a mantener y medición,

- estar alineado con los objetivos y planes estratégicos de la organización,

- aportar a la organización un sistema integrado de gestión que apoye las decisiones de varios niveles: operaciones y producción, abastecimiento, comercio exterior, comercialización, marketing, administración, finanzas y capital humano.

Al relacionar la contabilidad gerencial con la temática del presente artículo, y tomando como base los conceptos citados por Herrscher (Soto, 2011), se concibe a la misma como que: 
- representa la culminación de las técnicas contables hacia adentro de la empresa. Existen determinados indicadores de gestión propios de la actividad forestal (EBITDA Forestal, KT Forestal, etc.) que tienen sus propias técnicas contables de determinación y rescate de datos, y superan los considerandos de las normas contables generalmente aceptadas,

- incorpora a los elementos materiales del sistema contable un todo orgánico de herramientas modernas de planeamiento y gestión (ej. plan estratégico, panel de control e indicadores propios de la industria, etc.). La importancia de estas herramientas toma más consideración cuando se gestionan activos a largo plazo como los bosques cultivados,

- se orienta a la eficiencia de la gestión empresarial y la permanente toma de decisiones, como la gestión, control del cambio y transformación biológica,

- representa el sistema de información cuantitativo por excelencia de la empresa. Existen indicadores de gestión propios de la actividad (ej. porcentaje de madera pulpable y aserrable, rendimiento $\mathrm{m}^{3}$ por hectárea, etc.).

\section{Utilidad de la información de gestión para administrar y gestionar bosques cultivados}

La actividad forestal produce bienes económicos a partir de la combinación del esfuerzo del hombre por su gestión y por la naturaleza, para favorecer la actividad biológica de las plantaciones incluyendo su reproducción, mejoramiento $\mathrm{y} / 0$ crecimiento (Torres, 2010). Esta capacidad de cambio debe ser manejada en forma objetiva por el hombre (gestión del cambio) y medida y controlada por el control gerencial (medición del cambio).

Las decisiones gerenciales en la vida de la plantación son muy trascendentes y difíciles de modificar. El factor humano interviene en el cambio a través de sus diferentes actividades y realiza el control en la calidad biológica y cantidad de las plantaciones en forma objetiva.
Este enfoque de gerenciamiento:

- facilita la transformación biológica mejorando 0 estabilizando las condiciones necesarias para que el proceso biológico tenga lugar (ej. humedad del suelo, nivel de fertilizantes, raleos y podas escalonadas, turnos de corta, control de malezas, control de hormigas, densidad de plantación, etc.),

- se realiza en forma activa para facilitar la transformación biológica, lo que se diferencia de un gerenciamiento desmesurado (deforestación). La forestación manejada y gerenciada facilita el mejoramiento de la calidad y cantidad de plantaciones.

Las decisiones que toman los administradores de un ente forestal, a través de las mejores técnicas silviculturales, influyen en el control de costos, pero deben nutrirse de información de gestión en cantidad y calidad necesaria, relativa a la operatoria de los bosques cultivados a efectos de monitorear y controlar su gestión.

El planeamiento estratégico a través de sus objetivos, metas, indicadores y programas de acción representa una herramienta muy útil a estos efectos. Será necesario un sistema de información integrado de datos (panel de control, reportes e indicadores de gestión) que brinde información cuantitativa y cualitativa de la evolución del ciclo vital de las plantaciones forestales y sobre aspectos integrales de la marcha del negocio: financieros, comerciales, producción y tecnología, ambientales y sociales, para la toma de decisiones estratégicas a los usuarios internos del ente.

Si bien algunos de estos aspectos son cuantitativos y no están expresados sólo en términos monetarios y otros son más cualitativos o descriptivos, hay dos elementos que cruzan transversalmente a todo este proceso:

- un sistema integral de información contable y de gestión (base de datos) del ente,

- un sistema de decisiones que se van tomando durante el ciclo biológico por los distintos niveles organizacionales para que el proceso sea más eficiente. 
Lo indicado lo ratifica García Casella citando a Herrscher en la obra de Soto (2011) donde menciona que la contabilidad gerencial logra su máxima eficiencia en la gestión empresarial a través de un adecuado planeamiento y un eficaz control de las decisiones tomadas. En estas acciones radica la importancia del segmento de contabilidad de gestión en la temática.

\section{La capacidad de producción} de bosques cultivados y la contabilidad de gestión

El concepto de «producción» (o crecimiento) para los activos biológicos forestales, establecido por las normas contables, considera una variación patrimonial no vinculada directamente con los costos incurridos históricos. La inversión en estos activos, su gestión y control desencadenan un proceso de incremento de riqueza que en el curso normal de los negocios es irreversible, no siendo por lo tanto el costo incurrido representativo del valor del bien (Rudi, 2005). Este autor menciona que la comunidad contable viene sosteniendo que la acción de producir y no de vender, al gestionar activos biológicos, genera un hecho novedoso en la relación entre contabilidad patrimonial y contabilidad de gestión, ya que:

- el concepto de «producir» se aproxima más a un concepto económico de beneficio y permite, en consecuencia, a la contabilidad de gestión obtener informes más aptos para la gestión empresarial,

- al determinar el resultado solamente por la generación de ingresos, se ignora la existencia de otra función tan importante como aquella, que es producción,

- al vender sólo se cambia la naturaleza del activo, ya que pasan bienes del inventario circulante a cuenta por cobrar 0 disponible. Es decir, se establece con terceros una relación de tipo jurídico al momento de la venta.

Por lo tanto, dentro del proceso de información contable el incremento del valor de los bosques por producción (crecimiento) genera un resultado (posi- tivo o negativo) propio que debe ser reflejado en la información gerencial del ente, con independencia del resultado bruto de ventas generado por la comercialización. En estas afirmaciones reside otro pilar de importancia de la contabilidad de gestión en la temática, ya que la misma está más emparentada con el concepto de «capital físico» a mantener que con el concepto de «capital financiero» (características propias del modelo de contabilidad patrimonial).

\section{Planeamiento estratégico en la actividad forestal}

\section{Características de un planeamiento estratégico eficiente}

La planificación estratégica es el proceso sistemático de desarrollo e implementación de planes para alcanzar propósitos u objetivos (Espinoza, 2012).

Para que un sistema de control de gestión sea maduro y eficiente el órgano volitivo y la alta gerencia del ente deben establecer, en primera instancia, un rango de políticas e «intenciones» estratégicas basadas en la fijación de:

- una misión y visión,

- objetivos organizacionales estratégicos por área de responsabilidad.

Se trata del inicio del proceso de planificación estratégica a largo plazo y debe estar representado por un mapa estratégico que relacione los distintos objetivos de las áreas y cómo los mismos fluyen en forma coordinada al cumplimiento de la misión y visión del ente.

A partir de estas decisiones estratégicas, y descendiendo en la escala jerárquica de la organización, los administradores deben elaborar una segunda etapa de planificación, a corto y mediano plazo que incluya:

- metas cuantificables (monetarias y no monetarias) para monitorear el cumplimiento de cada objetivo estratégico, 
- una serie de indicadores clave que contribuyen a la medición de los logros reales versus metas, - programas de acción para el cumplimiento de los indicadores y objetivos estratégicos.

Las empresas que desarrollan un proceso eficiente de control de gestión:

- entienden los conceptos básicos de planificación estratégica,

- reconocen la importancia de la gestión por resultados,

- enfrentan el presente y el futuro organizacional conociendo que hace hoy el ente, hacia donde va y que quiere lograr (misión y visión), sin que el azar intervenga,

- planean antes de iniciar todo el proceso administrativo y de control,

- cuentan con parámetros e indicadores que permiten evaluar los resultados de su gestión.

\section{Proceso y metodología}

\section{en la elaboración del planeamiento} estratégico en una sociedad forestal

A continuación se desarrolla la propuesta principal del presente trabajo respecto del diseño de un planeamiento estratégico en una sociedad dedicada a la actividad silvícola. Si bien se establece una metodología general respecto de la fijación de misión-visión, dimensiones de análisis, objetivos estratégicos, indicadores de control y planes de acción, la misma puede ser adaptable y aplicable a todo tipo de actividad.

Los pasos que se explicarán para la elaboración del mapa estratégico son los siguientes:

A. Declaración de misión y visión

B. Definición de dimensiones de análisis

C. Definición de objetivos estratégicos y mapa estratégico

D. Definición y medición de indicadores estratégicos

\section{A. Declaración de misión y visión. El gran obje- tivo estratégico}

La misión y visión de la empresa es una declaración tácita y compartida entre todos los integrantes de la organización y sus grupos de interés.

Una «declaración de visión» y describe en términos gráficos dónde la empresa quiere estar en el futuro mediante un carácter inspirador y motivador (Espinoza, 2012). Describe cómo la organización «visualiza» el posicionamiento de la misma en los próximos 15020 años, si todo funcionase exactamente como cabe esperar.

Una «declaración de misión» es similar, salvo en que es algo más inmediato. Detalla qué tipo de programas e iniciativas impulsará la organización para aproximarse a la visión que ha definido. Una declaración efectiva de visión debe ser:

- clara y alejada de la ambigüedad,

- que dibuje una escena,

- que describa el futuro,

- que sea fácil de recordar y con la que uno pueda comprometerse,

- que incluya aspiraciones que sean realistas,

- que esté alineada con los valores y cultura de la organización,

- que esté orientada a las necesidades del cliente y grupos de interés.

Como punto de partida de su planeamiento estratégico, la organización debería proceder a definir el gran objetivo estratégico de su negocio.

La misión se debe definir principalmente a través de las siguientes preguntas: ¿cuál es la actividad de la empresa en el mercado?, ¿qué hace, cuál es su negocio y a qué se dedica?, ¿cuál es su razón de ser?, ¿cuál es su ventaja competitiva?, ¿qué la diferencia de sus competidores? (Espinoza, 2012).

La visión, por otra parte, define las metas que pretende conseguir el ente a futuro. Aquí se deben responder a las siguientes preguntas para lograr su definición: ¿qué quiere lograr la misma?, ¿dónde quiere estar en el futuro? (Espinoza, 2012). 
En la temática del artículo, la misión y visión deberían permitir lograr equilibrio entre producir y vender madera en cantidad y calidad en forma rentable y sostenible, logrando alineación con el medio ambiente, la comunidad y medición de impactos, riesgos y oportunidades socioambientales.

Bajo la perspectiva de rentabilidad económica, la empresa forestal produce bienes económicos a partir de la combinación de la naturaleza y la gestión de la actividad del cambio por el hombre, tendiente a favorecer la reproducción, el mejoramiento y el crecimiento de la forestación. Su actividad productiva es la que toma significación para la determinación del resultado económico y no el momento de la venta de los bienes producidos (Rudi, 2005). La organización, a través de su proceso de gestión, debe crear valor económico y potenciar el crecimiento de sus bosques.

Desde la perspectiva ambiental, la actividad silvícola tiene fuerte impacto en el medioambiente. El ciclo vital de las plantaciones y su transformación biológica son dependientes de una combinación de recursos naturales (sol, agua, aire y suelo) y cualquier decisión del ser humano sobre la gestión de los mismos afecta el medioambiente.

Por último y desde el punto de vista social, la forestación tiene relación directa con la comunidad, cuyos aspectos fácticos los recoge la contabilidad social. Involucra actores, comunidades y unidades de producción diferentes que facilitan y necesitan mercados activos para operar (contratistas, aserraderos, leñeros, empresas de servicios, etc.). Así también, los productos madereros y no madereros se utilizan para satisfacer necesidades sociales básicas (ej. comida, medicamentos, alimentos, refugio, elementos de transporte, energía, construcción, etc.).

En consecuencia, podemos imaginar un ejemplo de «misión y visión» de una empresa forestal como sigue (Figura 1):
Ejemplo de MISIÓN y VISIÓN de una empresa forestal

Crear valor económico de los bosques (MISIÓN), con creación de valor ambiental y valor social en forma sostenible a futuro (VISIÓN).

-Meta del triple resultado-

Figura 1. Ejemplo de misión y visión del ente forestal

PROPUESTA DE MAPA ESTRATÉGICO DE SOCIEDAD FORESTAL META DEL TRIPLE RESULTADO

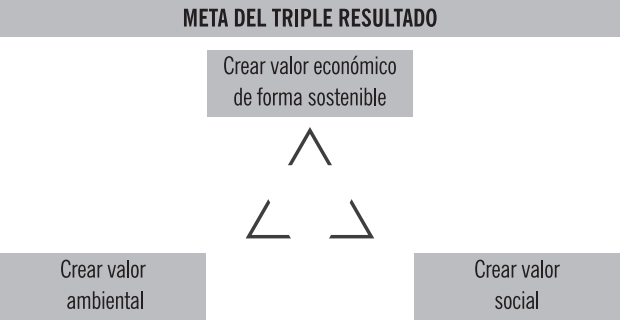

Fuente: Elaboración propia

\section{B. Definición de dimensiones de análisis}

Luego de la definición de misión y visión se deben establecer las dimensiones de análisis, alineadas con las distintas áreas de la empresa: Administración y Finanzas, Comercialización, Patrimonio Forestal, Producción Forestal, Capital Humano, Responsabilidad Social y Ambiental. Todas las áreas deben interactuar y colaborar con el cumplimiento de sus objetivos individuales al cumplimiento del objetivo estratégico de la sociedad en su conjunto.

Las dimensiones de una empresa forestal podrían identificarse como siguen (Figura 2):

Figura 2. Dimensiones de análisis del plan estratégico

\begin{tabular}{l}
\hline Financiera \\
\hline Clientes \\
\hline Patrimonio Forestal, Procesos y Tecnología \\
\hline Responsabilidad Social y Ambiental \\
\hline Aprendizaje y Crecimiento \\
\hline
\end{tabular}

Fuente: Elaboración propia 
- Dimensión financiera: representa la mirada desde el punto de vista del accionista. Debe responder a la pregunta: ¿cómo la sociedad genera valor para sus accionistas? No se refiere a los objetivos del área de finanzas de la sociedad, sino en el foco de los objetivos de: valor económico de la empresa, crecimiento de los ingresos, utilización de los activos o reducción de costos y gastos.

- Dimensión clientes: es la mirada desde el mercado y apunta a la percepción que tiene el cliente de la empresa. Debe responder a las preguntas: ¿qué satisface a los clientes?, ¿cómo ser preferidos por los clientes? No se refiere a los objetivos del área comercial de la organización, sino que constituye una mirada externa, la que los clientes tienen de la empresa. Hace foco en los objetivos de: satisfacción de clientes, retención de clientes, incorporación de nuevos clientes y participación en el mercado.

- Dimensión proceso de patrimonio forestal, procesos y tecnología: es la mirada hacia el interior del ente: identificación de los procesos críticos (operativos) para satisfacer a clientes y accionistas. Debe responder a las preguntas: ¿en qué procesos la empresa debe ser excelente?, ¿qué es lo que tiene que mejorar? Hace foco en los objetivos de innovación (desarrollo de productos, alianzas, etc.), procesos operativos (costos, tiempo y calidad) y logísticos.

- Dimensión responsabilidad social y ambiental: representa la administración de las relaciones de la sociedad y el medioambiente y mirado desde el punto de vista del impacto directo sobre los públicos interesados y el medio ambiente. Debe responder a las preguntas: ¿cómo se asegura la empresa su «licencia social para operar»?

- Dimensión aprendizaje y crecimiento: es la base del mapa estratégico. Representa los objetivos para impulsar el aprendizaje del personal y permitir de esta manera el crecimiento de la organización. Consiste en asegurar las competencias y motivaciones que deben tener los colaboradores para apoyar el logro de la estrategia. Debe responder a la pregunta: ien qué y cómo la sociedad y sus colaboradores deben capacitarse para mejorar y crear valor?

\section{Definición de objetivos estratégicos y mapa estratégico}

Definidas la misión-visión y dimensiones de análisis, la gerencia responsable de cada dimensión debe determinar aquellos pocos objetivos claves que deben cumplir y definirlos como «estratégicos» para su área de responsabilidad. Estos representan el conjunto de objetivos individuales para el cumplimiento de la misión y visión predefinidos. Representan las prioridades que deberá seguir, controlar, medir y corregir cada área ya que de su cumplimiento depende, en gran parte, el cumplimiento del gran objetivo estratégico en su conjunto.

Los objetivos estratégicos deben ser específicos, medibles, alcanzables, realistas y con plazo de cumplimiento. Representan 10-20 áreas de enfoque clave para lograr en un futuro inmediato (1 a 3 años) avances significativos («saltos cualitativos»), pero no mejoras continuas. Cada objetivo debe poder contribuir para cumplir la visión y misión del ente y ser suficiente para que el área responsable logre su propia visión y misión.

Para poder controlar el seguimiento de los objetivos estratégicos de cada área y su cumplimiento final será necesario establecer un mapa estratégico. Es una representación gráfica de los objetivos estratégicos y sus relaciones de causa y efecto. El mismo debe ser capaz de contar en forma simple la estrategia de la sociedad forestal y exponer cómo cada área y objetivo estratégico contribuye a cumplir la visión y misión. Simplifica el monitoreo de la estrategia y su uso en el proceso de planeamiento estratégico y permite dar señales de alerta, permitiendo tomar medidas correctivas a tiempo.

A continuación, en la Figura 3 se presenta una representación gráfica de mapa estratégico que relaciona la visión y misión, dimensiones de análisis y objetivos estratégicos. Se proponen 17 objetivos estratégicos para las diferentes dimensiones ya definidas. 
Figura 3. Modelo de mapa estratégico de empresa forestal (visión y misión, dimensiones y objetivos estratégicos)

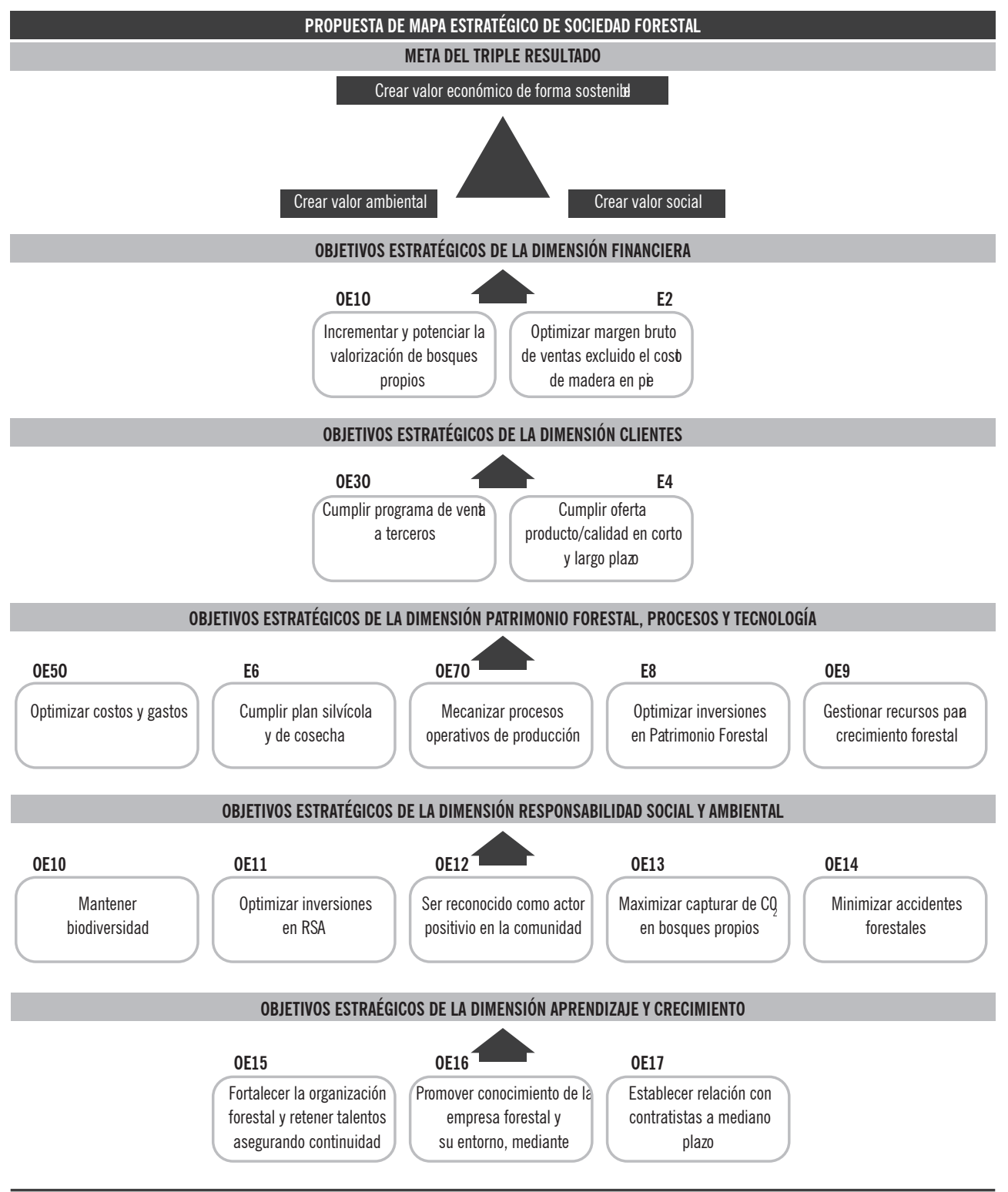

Fuente: Elaboración propia

Objetivos estratégicos de la dimensión financiera para empresa forestal

Apuntan a la forma de generar valor a los accionistas y crear valor económico para la empresa, con crecimiento de los ingresos, margen de rentabilidad y EBITDA. Los objetivos propuestos son: OE 1: Incrementar y potenciar la valorización de bosques propios

OE 2: Optimizar margen bruto de ventas excluido el costo de madera en pie 
Objetivos estratégicos de la dimensión clientes para empresa forestal

Apuntan al mercado y a la percepción que tienen los clientes de la sociedad haciendo foco en los objetivos de: fidelización, satisfacción de clientes y retención de clientes, incorporación de nuevos clientes y participación en el mercado. Los objetivos propuestos son:

OE 3: Cumplir programa de venta a terceros

OE 4: Cumplir oferta producto/calidad en el corto y largo plazo

Objetivos estratégicos de la dimensión proceso de patrimonio forestal, procesos y tecnología para empresa forestal

Apuntan a identificar procesos críticos (operativos) para satisfacer a clientes y accionistas y mejorar la rentabilidad. Hacen foco en optimizar costos y gastos, cumplir planes silvícolas y de plantación, optimizar procesos operativos de producción. Los objetivos propuestos son:

OE 5: Optimizar costos y gastos

OE 6: Cumplir plan silvícola y de cosecha

OE 7: Mecanizar procesos operativos de producción

OE 8: Optimizar inversiones en patrimonio forestal

OE 9: Gestionar recursos para crecimiento forestal

Objetivos estratégicos de la dimensión responsabilidad social y ambiental para empresas forestales Apuntan a identificar todos los efectos del impacto y compromiso con el medio ambiente y la comunidad. Los objetivos propuestos son:

OE 10: Mantener biodiversidad

OE 11: Optimizar inversiones en responsabilidad social y ambiental

OE 12: Ser reconocido como actor positivo en la comunidad

OE 13: Maximizar captura de CO2 en bosques propios

OE 14: Minimizar accidentes forestales
Objetivos estratégicos de la dimensión aprendizaje y crecimiento para empresas forestales

Apunta en asegurar las competencias y motivaciones que deben tener sus colaboradores para apoyar el logro de la estrategia. Los objetivos propuestos son:

OE 15: Fortalecer la organización forestal y retener talentos asegurando continuidad

OE 16: Promover conocimiento de la empresa forestal y su entorno mediante capacitaciones

OE 17: Establecer relación con contratistas a mediano plazo

\section{Definición y medición de indicadores estra- tégicos}

En esta etapa del planeamiento y anclados a los objetivos estratégicos para cada dimensión, se deben definir aquellos indicadores (fórmulas macro y micro económicas, operativas, sociales y ambientales) que permitan gestionar y medir los resultados, controlar y corregir los desvíos a través de las mejores decisiones gerenciales. Un indicador es un valor que refleja el grado de cumplimiento de un objetivo estratégico.

Cada objetivo estratégico puede tener uno o varios indicadores asociados. Por otro lado, cada indicador debería contener su unidad de medida y frecuencia de medición. En este panel se vuelcan datos plan para cada indicador (estimados por las diferentes áreas) y datos reales de avance en función de la frecuencia de la medición.

Los indicadores deben:

- medir el cumplimiento del objetivo para el que fueron diseñados,

- ser prácticos y utilizar datos que estén disponibles en forma oportuna con un esfuerzo razonable (tiempo del personal, costos, etc.),

- permitir la comparación a través del tiempo y operaciones de otras sociedades,

- ser útiles para la toma de decisiones,

- ser los más relevantes posibles para la gestión y control del ente. 
A continuación se desarrolla una explicación de los indicadores propuestos para cada objetivo estratégico y en cada dimensión de análisis definida, con indicación de la unidad de medida y frecuencia de medición para cada indicador individual.
Los indicadores apropiados para medir el grado de cumplimiento de los objetivos en la dimensión financiera de una empresa forestal serían los siguientes (Tabla 1):

Tabla 1. Propuesta de indicadores estratégico para la dimensión financiera (empresa forestal)

\begin{tabular}{|c|c|c|c|c|c|c|c|}
\hline $\begin{array}{l}\# \\
\mathrm{OE}\end{array}$ & $\begin{array}{l}\text { NOMBRE OBJETIVO } \\
\text { ESTRATÉGICO }\end{array}$ & $\begin{array}{l}\# \\
\text { IND }\end{array}$ & NOMBRE INDICADOR & $\begin{array}{l}\text { UNIDAD DE } \\
\text { MEDIDA }\end{array}$ & $\begin{array}{l}\text { FREC. } \\
\text { MED. }\end{array}$ & $\begin{array}{l}\text { REAL } \\
\text { MENSUAL }\end{array}$ & $\begin{array}{l}\text { PLAN } \\
\text { MENSUAL }\end{array}$ \\
\hline & \multicolumn{7}{|l|}{ DIMENSIÓN FINANCIERA } \\
\hline OE01 & $\begin{array}{l}\text { Incrementar y potenciar } \\
\text { la valorización de } \\
\text { bosques propios }\end{array}$ & 1 & $\begin{array}{l}\text { Tasación forestal mediante flujos descon- } \\
\text { tados }\end{array}$ & MUSD & Anual & & \\
\hline \multirow[t]{6}{*}{ OE02 } & \multirow{6}{*}{$\begin{array}{l}\text { Optimizar margen bruto } \\
\text { de ventas excluido el } \\
\text { costo de madera en pie }\end{array}$} & 2 & Margen total excluido costo de madera en pie & MUSD & Mensual & & \\
\hline & & 3 & Margen neto pie eucaliptus aserrable (total) & USD $/ \mathrm{m}^{3}$ & Mensual & & \\
\hline & & 4 & Margen neto pie eucaliptus pulpable (total) & USD $/ \mathrm{m}^{3}$ & Mensual & & \\
\hline & & 5 & EBITDA Forestal & MUSD & Mensual & & \\
\hline & & 6 & EBITDA / (KT + Activo Fijo Neto) & $\%$ & Trimestral & & \\
\hline & & 7 & Rotación del KT (KT Forestal / Ventas) & $\%$ & Mensual & & \\
\hline
\end{tabular}

Fuente: Elaboración propia

Indicador 1: Tasación forestal mediante flujos descontados: corresponde al valor absoluto de la tasación final al momento de medición mediante valor actual neto de flujos descontados (ingresos y egresos) de todo el patrimonio forestal. Mide crecimiento del patrimonio forestal con frecuencia anual, a efectos de contribuir al objetivo de incremento de los bosques en forma económica, social y ambiental. Indicador 2: Margen total excluido costo de madera en pie: mide el margen bruto de ventas total en valores monetarios absolutos. Para su cuantificación se consideran ingresos por ventas, menos costos variables de ventas (cosecha, carga y flete). Por lo tanto, no se considera el costo por consumo de materia prima propia (costo de la madera consumida y vendida) ya que en definitiva lo que se quiere medir es el valor neto en pie del monte. De medición mensual.
Indicadores 3 y 4: Margen neto en pie unitario por especie y producto: iguales características que el indicador anterior pero en este caso se mide margen en valores monetarios por $\mathrm{m}^{3}$ vendido, por especie forestal (ej. eucaliptus, pino, etc.) y producto (aserrable, pulpable, podado, etc.). Ambos también de medición mensual.

Indicador 5: EBITDA Forestal: la herramienta principal de medición de rentabilidad de las empresas forestales no integradas y corresponde a un concepto más emparentado con la contabilidad de gestión que con la contabilidad patrimonial.

Se mide en valores monetarios absolutos y tiene en cuenta el flujo efectivo generado por la operación (Resultado Operacional antes de intereses e impuestos), sin considerar aquellos conceptos que no generan flujo (ej. depreciaciones). En el caso de esta industria se excluye a efectos del cálculo 
de este indicador el costo de materia prima madera - propia que fue consumida y vendida y no generó erogación de fondos. De medición mensual. Indicador 6: EBITDA / (KT+Activo Fijo Neto): muestra el porcentaje que representa el EBITDA Forestal en relación con el capital de trabajo (KT) de la sociedad más los activos fijos netos, como una medida de rentabilidad de la inversión. El capital de trabajo forestal (KT Forestal) está representado por las cuentas a cobrar circulantes menos las cuentas a pagar circulantes (ambas cuentas operativas sin considerar las cuentas de impuestos a cobrar o pagar). El Activo Fijo Neto incluye el valor residual de los activos fijos y el valor de las plantaciones corrientes y no corrientes en pie. De medición trimestral.

Indicador 7: Rotación del KT: indica el porcentaje que el Capital de trabajo Forestal (KT Forestal) está contenido en las ventas, es decir la rotación del KT Forestal en el período. El dato de Ventas para este indicador corresponde al promedio trimestral. Se mide en forma mensual.

Los indicadores apropiados para medir el grado de cumplimiento de los objetivos en la dimensión clientes de una empresa forestal serían los de la Tabla 2 (todos de frecuencia de medición mensual):

Tabla 2. Propuesta de indicadores estratégico para la dimensión clientes (empresa forestal)

\begin{tabular}{|c|c|c|c|c|c|c|c|}
\hline $\begin{array}{l}\# \\
0 \mathrm{E} \\
\end{array}$ & $\begin{array}{l}\text { NOMBREE OBJETIVO } \\
\text { ESTRATÉGICO }\end{array}$ & $\begin{array}{l}\# \\
\text { IND }\end{array}$ & NOMBRE INDICADOR & $\begin{array}{l}\text { UNIDAD DE } \\
\text { MEDIDA }\end{array}$ & $\begin{array}{l}\text { FREC. } \\
\text { MED. }\end{array}$ & $\begin{array}{l}\text { REAL } \\
\text { MENSUAL }\end{array}$ & $\begin{array}{l}\text { PLAN } \\
\text { MENSUAL }\end{array}$ \\
\hline & DIMENSIÓN CLIENTES & & & & & & \\
\hline OE03 & $\begin{array}{l}\text { Cumplir programa de } \\
\text { venta a terceros }\end{array}$ & 8 & Volumen de venta a terceros & $m^{3}$ & Mensual & & \\
\hline \multirow[t]{6}{*}{ 0E04 } & \multirow{6}{*}{$\begin{array}{l}\text { Cumplir oferta producto/ } \\
\text { calidad en el corto } \\
\text { y largo plazo }\end{array}$} & 9 & Volumen de venta total & $\mathrm{m}^{3}$ & Mensual & & \\
\hline & & 10 & Volumen de venta en pie & $\mathrm{m}^{3}$ & Mensual & & \\
\hline & & 11 & Volumen pulpable / Volumen Total & $\%$ & Mensual & & \\
\hline & & 12 & Volumen aserrable / Volumen total & $\%$ & Mensual & & \\
\hline & & 13 & Volumen podado / Volumen total & $\%$ & Mensual & & \\
\hline & & 14 & Volumen de venta inter-compañía & $\mathrm{m}^{3}$ & Mensual & & \\
\hline
\end{tabular}

Fuente: Elaboración propia

Indicador 8: Volumen de venta a terceros: mide en $\mathrm{m}^{3}$ el grado de cumplimiento de las metas de ventas programadas por entregas a terceros clientes (no se incluyen en este indicador ventas a sociedades vinculadas).

Indicador 9: Volumen de venta total: mide en $\mathrm{m}^{3}$ el grado de cumplimiento de las metas previstas en los programas operativos respecto de los volúmenes totales de venta (terceros y compañías vinculadas) tanto en lo referido a la modalidad de venta en aserradero 0 plantas de celulosa de madera elaborada, como ventas de plantaciones en pie.
Indicador 10: Volumen de venta en pie: mide en $\mathrm{m}^{3}$ el grado de cumplimiento de las metas previstas en los programas operativos respecto de los volúmenes reales logrados por venta de plantaciones en pie en el bosque.

Indicador 11: Volumen pulpable / Volumen Total: mide el grado de cumplimiento en porcentaje por venta de madera pulpable sobre el total de la venta La madera pulpable es aquella fina y de inferior calidad (entre 8 a $15 \mathrm{~cm}$ de diámetro), de menor precio de venta demandada por las empresas celulósicas y de paneles. 
Indicador 12: Volumen aserrable / Volumen Total: mide el grado de cumplimiento en porcentaje por venta de madera aserrable sobre el total de la venta. La madera aserrable es aquella de calidad intermedia (entre 16 a $28 \mathrm{~cm}$ de diámetro) y que demanda básicamente los aserraderos.

Indicador 13: Volumen podado / Volumen Total: mide el grado de cumplimiento en porcentaje por venta de madera podada sobre el total de la venta. La madera podada es aquella de calidad premium (superior a $28 \mathrm{~cm}$ de diámetro), de mayor precio de venta y destinada a industrias de enchapado.
Indicador 14: Volumen de venta inter-compañía: mide en $\mathrm{m}^{3}$ el grado de cumplimiento de las metas previstas en los programas operativos respecto de las entregas reales a clientes relacionados 0 vinculados.

Los indicadores apropiados para medir el grado de cumplimiento de los objetivos en la dimensión proceso de patrimonio forestal, procesos y tecnología de una empresa forestal serían los siguientes (Tabla 3):

Tabla 3. Propuesta de indicadores estratégico para la dimensión patrimonio forestal, procesos y tecnología (empresa forestal)

\begin{tabular}{|c|c|c|c|c|c|c|c|}
\hline $\begin{array}{l}\# \\
\# \\
\mathrm{OE}\end{array}$ & $\begin{array}{l}\text { NOMBRE OBJETIVO } \\
\text { ESTRATÉGICO }\end{array}$ & $\begin{array}{l}\# \\
\text { IND }\end{array}$ & NOMBRE INDICADOR & $\begin{array}{l}\text { UNIDAD DE } \\
\text { MEDIDA }\end{array}$ & $\begin{array}{l}\text { FREC. } \\
\text { MED. }\end{array}$ & $\begin{array}{l}\text { REAL } \\
\text { MENSUAL }\end{array}$ & $\begin{array}{l}\text { PLAN } \\
\text { MENSUAL }\end{array}$ \\
\hline & \multicolumn{7}{|c|}{ DIMENSIÓN PROCESO DE PATRIMONIO FORESTAL, PROCESOS Y TECNOLOGÍA } \\
\hline \multirow[t]{6}{*}{ OE05 } & Optimizar costos & 15 & Costos de producción unitarios & $\mathrm{USD} / \mathrm{m}^{3}$ & Mensual & & \\
\hline & y gastos & 16 & Costos directos silvícolas & MUS\$ & Trimestral & & \\
\hline & & 17 & Costos de reforestación & USD/Ha. & Anual & & \\
\hline & & 18 & Costo de plantación & USD/Ha. & Anual & & \\
\hline & & 19 & Costo de poda & USD/Ha. & Mensual & & \\
\hline & & 20 & Costo de raleo desecho & USD/Ha. & Mensual & & \\
\hline \multirow[t]{9}{*}{ OE06 } & Cumplir plan silvícola & 21 & Superficie cosechada total & Has. & mensual & & \\
\hline & y de cosecha & 22 & Cumplimiento plan silvícola en sup. (Has) & Has. & Trimestral & & \\
\hline & & 23 & Cumplimieto plan silvicola en valores & MUSD & Trimestral & & \\
\hline & & 24 & $\mathrm{~N}^{\circ}$ de plantas de replante/ $\mathrm{N}^{\circ}$ de plantas totales & $\%$ & Anual & & \\
\hline & & 25 & Superficie de plantación & Has. & Mensual & & \\
\hline & & 26 & Superficie de poda & Has. & Mensual & & \\
\hline & & 27 & Superficie de raleo desecho & Has. & Mensual & & \\
\hline & & 28 & $\begin{array}{l}\text { Cumplimiento planificación de manejo } \\
\text { trimestral (poda-raleo) }\end{array}$ & $\%$ & Trimestral & & \\
\hline & & 29 & $\begin{array}{l}\text { Evolución productividad potencial } \\
\text { de plantaciones }\end{array}$ & $\begin{array}{l}\mathrm{m}^{3} / \mathrm{ha} \text {./ } \\
\text { año }\end{array}$ & Anual & & \\
\hline \multirow[t]{2}{*}{ OE07 } & $\begin{array}{l}\text { Mecanizar procesos } \\
\text { operativos de producción }\end{array}$ & 30 & Productividad por operario forestal & $\begin{array}{l}\mathrm{m}^{3} / \mathrm{hom}- \\
\mathrm{bre} / \mathrm{mes}\end{array}$ & mensual & & \\
\hline & & 31 & $\begin{array}{l}\text { Volumen de cosecha y raleo mecanizado / } \\
\text { Volumen Total }\end{array}$ & $\%$ & mensual & & \\
\hline \multirow[t]{3}{*}{ OE08 } & Optimizar inversiones & 32 & Gastos Indirectos en Patrimonio Forestal & MUSD & Mensual & & \\
\hline & en Patrimonio Forestal & 33 & $\begin{array}{l}\text { Programa de inversiones en Patrimonio } \\
\text { Forestal }\end{array}$ & MUSD & Trimestral & & \\
\hline & [Continúa pág. sgte.] & & & & & & \\
\hline
\end{tabular}




\begin{tabular}{|c|c|c|c|c|c|c|c|}
\hline $\begin{array}{l}\# \\
\mathrm{E}\end{array}$ & $\begin{array}{l}\text { NOMBRE OBJETIVO } \\
\text { ESTRATÉGICO }\end{array}$ & $\begin{array}{l}\# \\
\text { IND }\end{array}$ & NOMBRE INDICADOR & $\begin{array}{l}\text { UNIDAD DE } \\
\text { MEDIDA }\end{array}$ & $\begin{array}{l}\text { FREC. } \\
\text { MED. }\end{array}$ & $\begin{array}{l}\text { REAL } \\
\text { MENSUAL }\end{array}$ & $\begin{array}{l}\text { PLAN } \\
\text { MENSUAL }\end{array}$ \\
\hline & \multicolumn{7}{|c|}{ DIMENSIÓN PROCESO DE PATRIMONIO FORESTAL, PROCESOS Y TECNOLOGÍA } \\
\hline \multirow[t]{5}{*}{ OE08 } & Optimizar inversiones & 34 & Disposición de residuos & Has. & Mensual & & \\
\hline & en Patrimonio Forestal & 35 & Costo en taipas & Has. & Mensual & & \\
\hline & [Continuación] & 36 & Herbicida preplantacion & Has. & Mensual & & \\
\hline & & 37 & Costo en rastra / rome & Has. & Mensual & & \\
\hline & & 38 & Cultivo quimico preplantacion & Has. & Mensual & & \\
\hline OE09 & $\begin{array}{l}\text { Gestionar recursos para } \\
\text { crecimiento forestal }\end{array}$ & 39 & Otras hectáreas compradas & Has. & Trimestral & & \\
\hline
\end{tabular}

Fuente: Elaboración propia

Indicador 15: Costos de producción unitarios: mide el costo total variable de producción (cosecha de madera, carga y flete a destino del cliente) en valores monetarios absolutos y por $\mathrm{m}^{3}$ producido. Frecuencia de medición mensual.

Indicador 16: Costos directos silvícolas: informa en valores monetarios absolutos la inversión real en patrimonio forestal por costos silvícolas de mantención, protección, seguros y otros costos indirectos de administración forestal. Frecuencia de medición trimestral.

Indicador 17: Costo de reforestación: de medición anual, informa el costo real en valores monetarios y por hectárea de la actividad silvícola de reforestación de plantaciones, en lugares que han desaparecido los bosques anteriores por tala masiva 0 incendio.

Indicador 18: Costo de plantación: de medición anual, informa el costo real en valores monetarios por hectárea de plantación en lugares preparados especialmente para esta acción y en sitios donde antes no existían bosques.

Indicador 19: Costo de poda: corresponde a una actividad de manejo de plantación. Se muestra con este indicador el costo por las acciones de quite de ramas a distintas edades de la plantación y que son necesarias para que crezcan y se desarrollen con más fuerza las plantaciones. Se mide en valores monetarios por hectárea podada y con frecuencia de medición mensual.
Indicador 20: Costo de raleo desecho: mide el costo por hectárea de la intervención silvicultural denominada «raleo» y que reduce el número de plantas por hectárea con el objetivo de liberar de competencia y permitir el mejor crecimiento de las plantas que quedan en la plantación. Se mide en valores monetarios por hectárea raleada y de medición mensual.

Indicador 21: Superficie cosechada total: este indicador cuantifica el avance de las hectáreas de plantaciones cosechadas con frecuencia mensual.

Indicador 22: Cumplimiento plan silvícola en superficie (hectáreas): muestra el avance físico de las inversiones silvícolas en establecimiento, manejo y mantenimiento de plantaciones. De medición trimestral.

Indicador 23: Cumplimiento plan silvícola en valores: Ios mismos considerandos que el indicador anterior pero en valores absolutos monetarios. De medición trimestral.

Indicador 24: Número de plantas de replante / Número de plantas totales: muestra en porcentaje el éxito de la tarea de establecimiento de plantas nuevas al momento de plantar, con relación a las fallas que obligaron a replante. De medición anual al final del ciclo de plantación del año corriente.

Indicador 25: Superficie de plantación: de medición mensual muestra el avance de hectáreas de plantación en lugares preparados especialmente para esta acción y en sitios donde antes no existían bosques. 
Indicador 26: Superficie de poda: cantidad de hectáreas intervenida en esta acción de quite de ramas a distintas edades de la plantación. De medición mensual. Indicador 27: Superficie de raleo desecho: mide las hectáreas intervenidas por esta actividad que reduce el número de plantas por hectárea con el objetivo de liberar de competencia y permitir el mejor crecimiento de las plantas que quedan en la plantación. De de medición mensual.

Indicador 28: Cumplimiento planificación de manejo trimestral (poda-raleo): indica en porcentaje la relación de hectáreas reales manejadas con poda o raleo, sobre las hectáreas presupuestadas a manejar con poda y raleo. Mide el avance del plan silvícola de la sociedad.

Indicador 29: Evolución productividad potencial de plantaciones: representa el promedio ponderado del crecimiento anual de las plantaciones en $\mathrm{m}^{3}$ por hectárea y por año.

Indicador 30: Productividad por operario forestal: se mide en forma mensual, relacionando el volumen de producción cosechada mensual con la cantidad de operarios y los jornales trabajados en el mes. La unidad de medida es $\mathrm{m}^{3} /$ hombre/mes.

Indicador 31: Volumen de cosecha y raleo mecanizado sobre volumen total: mide el porcentaje de la cosecha total que fue realizado con procesos de cosecha mecanizada y no con mano de obra manual, lo que mitiga los riesgos de accidentes forestales. Se mide en porcentaje y en forma mensual.

Indicador 32: Gastos indirectos en Patrimonio Forestal: este indicador evalúa los gastos reales por administración del patrimonio forestal (administración, seguros, movilidad, vehículos, remuneraciones, etc.) incurridos por todo el personal directo y afectado a la administración de las plantaciones. De medición mensual.

Indicador 33: Programa de inversiones en Patrimonio Forestal: mide en valores monetarios absolutos, las inversiones realizadas en establecimiento, manejo, mantención y protección de plantaciones. Controla la desviación de éstas inversiones respecto de los programas operativos. De medición mensual.
Indicador 34: Disposición de residuos: mide la cantidad de hectáreas por mes sometidas a recolección, transporte, procesamiento, tratamiento 0 reciclaje del material de desecho producido por la actividad silvícola de la empresa.

Indicador 35: Costo en «taipas»: se trata de una intervención silvícola previa a la plantación y preparación del terreno, en aquellos lugares bajos que permanecen gran parte del año inundados. Se realizan luego de la nivelación del terreno y con el fin de lograr una elevación respecto del terreno natural y de esta forma colocar el plantín alejado de los excesos hídricos que retardan su crecimiento y dificultan la supervivencia. Esta actividad influye en los costos de plantación y se debe gestionar y medir por separado. De medición mensual y en hectáreas. Indicador 36: Herbicida preplantación: actividad de desmalezado o control de plantas invasoras, para facilitar la preparación del suelo, mediante la aplicación de herbicidas. También se mide por separado dado que es importante controlar y gestionar la misma. De medición mensual y en hectáreas.

Indicador 37: Costo en rastra/rome: se trata de una actividad de labranza mecánica con el uso de arado de discos que tiene como principal objetivo el control de malezas. El barbecho así logrado permite también una buena acumulación de humedad y una rápida mineralización de la materia orgánica. Se mide en forma mensual y en hectáreas.

Indicador 38: Cultivo químico preplantación: consiste en la fertilización de base mediante la aplicación de fertilizantes y nutrientes que se aplican conjuntamente con la preparación del suelo, antes de la plantación. De medición mensual y en hectáreas.

Indicador 39: Otras hectáreas compradas: este indicador mide la gestión para lograr la adquisición de nuevas hectáreas productivas para poder avanzar con el plan de plantación. De medición mensual y en hectáreas.

Los indicadores apropiados para medir el grado de cumplimiento de los objetivos en la dimensión responsabilidad social y ambiental de una empresa forestal serían los siguientes (Tabla 4): 
Mancini / Herramientas de contabilidad de gestión...

Tabla 4. Propuesta de indicadores estratégico para la dimensión ambiental y social (empresa forestal)

\begin{tabular}{|c|c|c|c|c|c|c|c|}
\hline $\begin{array}{l}\# \\
\mathrm{OE}\end{array}$ & $\begin{array}{l}\text { NOMBRE OBJETIVO } \\
\text { ESTRATÉGICO }\end{array}$ & $\begin{array}{l}\# \\
\text { IND }\end{array}$ & NOMBRE INDICADOR & $\begin{array}{l}\text { UNIDAD DE } \\
\text { MEDIDA }\end{array}$ & $\begin{array}{l}\text { FREC. } \\
\text { MED. }\end{array}$ & $\begin{array}{l}\text { REAL } \\
\text { MENSUAL }\end{array}$ & $\begin{array}{l}\text { PLAN } \\
\text { MENSUAL }\end{array}$ \\
\hline & \multicolumn{7}{|c|}{ DIMENSIÓN RESPONSABILIDAD SOCIAL Y AMBIENTAL } \\
\hline \multirow[t]{7}{*}{ 0E10 } & Mantener & 40 & Cumplimiento de vbles. biodiversidad de FSC & $\%$ & Anual & & \\
\hline & biodiversidad & 41 & Consumo de agroquímicos por ha. plantada & Its. / ha. & Anual & & \\
\hline & & 42 & $\mathrm{~N}^{\circ}$ cursos de agua monitoreados en calidad & $\begin{array}{l}\mathrm{n}^{0} \text { de cursos } \\
\text { de agua }\end{array}$ & Semestral & & \\
\hline & & 43 & Hectáreas de Reservas Naturales & Has. & Anual & & \\
\hline & & 44 & Has. de Reservas Naturales restauradas & Has. & Anual & & \\
\hline & & 45 & Certificación FSC & Hito & Anual & & \\
\hline & & 46 & $\begin{array}{l}\text { Hectáreas no quemadas de bosque nativo / } \\
\text { áreas de conservación }\end{array}$ & $\%$ & Semestral & & \\
\hline \multirow[t]{3}{*}{ OE11 } & Optimizar & 47 & Gastos Indirectos Administración RSA & MUSD & Mensual & & \\
\hline & inversiones & 48 & Gastos Indirectos Gestión Ambiental y Social & MUSD & Mensual & & \\
\hline & en RSA & 49 & Programa de inversiones RSA & MUSD & Anual & & \\
\hline \multirow[t]{4}{*}{ OE12 } & $\begin{array}{l}\text { Ser reconocido } \\
\text { como actor }\end{array}$ & 50 & Visitas a las Reservas Naturales & $\begin{array}{l}\text { Cantidad de } \\
\text { visitantes }\end{array}$ & Semestral & & \\
\hline & $\begin{array}{l}\text { positivo en } \\
\text { la comunidad }\end{array}$ & 51 & Gestión de comunidades & $\begin{array}{l}\text { Cant. de } \\
\text { terceros } \\
\text { gestionados }\end{array}$ & Trimestral & & \\
\hline & & 52 & $N^{0}$ de niños en prog, de extension ambiental & $\begin{array}{l}\text { Cantidad } \\
\text { de niños }\end{array}$ & Semestral & & \\
\hline & & 53 & $\begin{array}{l}\mathrm{N}^{\circ} \text { de personas internas capacitadas } \\
\text { en temas ambientales }\end{array}$ & $\begin{array}{l}\text { Cant. de } \\
\text { personas }\end{array}$ & Semestral & & \\
\hline \multirow[t]{2}{*}{ OE13 } & Maximizar captura & 54 & $\mathrm{CO}_{2}$ capturado en el año & Ton. & Anual & & \\
\hline & $\begin{array}{l}\text { de } \mathrm{CO}_{2} \text { en bosques } \\
\text { propios }\end{array}$ & 55 & Auditorías captura de carbono & $\begin{array}{l}\text { Cant. de } \\
\text { auditorías }\end{array}$ & Anual & & \\
\hline \multirow[t]{5}{*}{ OE14 } & $\begin{array}{l}\text { Minimizar } \\
\text { Accidentes } \\
\text { Forestales }\end{array}$ & 56 & Accidentes fatales & $\begin{array}{l}\text { Cant. de } \\
\text { accidentes } \\
\text { fatales }\end{array}$ & Mensual & & \\
\hline & & 57 & Incidentes reportados & $\begin{array}{l}\text { Cant. de } \\
\text { incidentes } \\
\text { reportados }\end{array}$ & Mensual & & \\
\hline & & 58 & IFAT Indice frecuencia de accidentes forestales & Indicador & Mensual & & \\
\hline & & 59 & ISAT Indice de severidad de accid. forestales & Indicador & Mensual & & \\
\hline & & 60 & Ausentismo colaboradores directos & $\%$ & Mensual & & \\
\hline
\end{tabular}

Fuente: Elaboración propia 
Indicador 40: Cumplimiento de variables de biodiversidad de FSC: el Consejo de Administración Forestal (en inglés: Forest Stewardship Council-FSC) es una organización no gubernamental de acreditación y certificación con sede en Bonn, Alemania. Su misión es promover el manejo ambientalmente apropiado, socialmente benéfico y económicamente viable de los bosques del mundo. Este indicador mide en porcentaje el logro en el cumplimiento de los estándares de biodiversidad exigidos por este organismo.

Indicador 41: Consumo de agroquímico por hectárea plantada: se monitorea el consumo de agroquímicos en litros por hectárea plantada, para gestionar y controlar la utilización de estos productos como una amenaza a la biodiversidad. De medición anual.

Indicador 42: Número de cursos de agua monitoreados en calidad: a través de este indicador se mide la cantidad de cursos de agua presentes en los predios forestales 0 áreas protegidas, que se han sometido al análisis de purificación y descomposición de residuos orgánicos presentes en los mismos. De medición anual y en valores absolutos. Indicador 43: Hectáreas de Reservas Naturales: superficie de tierra en hectáreas (si existen) dentro de los predios forestales, consagrada a la protección y al mantenimiento de la diversidad biológica, así como de los recursos naturales y los recursos culturales asociados, y manejada a través de medios jurídicos u otros medios eficaces. De medición anual.

Indicador 44: Hectáreas de Reservas naturales restauradas: corresponde a la medición en hectáreas de aquella superficie de reservas naturales que el ente forestal pudo restaurar de especies contaminantes al ecosistema natural y lograr de esta manera que el espacio pueda volver a su estado anterior (resiliencia).

Indicador 45: Certificación FSC: es la certificación que obtiene una sociedad forestal otorgada por el Forest Stewardship Council (FSC), que promueve el manejo ambiental apropiado, socialmente benéfico y económicamente viable de los bosques del mundo. Las empresas pueden demostrar a través de esta certificación un manejo sostenible de los bosques. Se mide como hito logrado o no (certificación 0 recertificación) en el panel de control.

Indicador 46: Hectáreas no quemadas de bosques nativos en función de las áreas destinadas a conservación: muestra el grado de compromiso de la empresa con la sostenibilidad. Mide en porcentaje la relación de hectáreas no sacrificadas de bosques nativos para de mantener la biodiversidad de las áreas protegidas. De medición anual.

Indicador 47: Gastos indirectos Administración RSA: muestra en valores monetarios absolutos las erogaciones destinadas a gastos fijos e indirectos a favor del sistema de responsabilidad social y ambiental de la empresa. De medición mensual

Indicador 48: Gastos indirectos gestión Ambiental y Social: muestra en valores monetarios absolutos las erogaciones destinadas a mantener la gestión de la responsabilidad ambiental y social de la empresa (asesorías técnicas, certificaciones, manejo de comunidades, etc.) De medición mensual.

Indicador 49: Programa de inversiones en RSA: se refiere a todas las inversiones en activos propios realizados por el ente para mantener el sistema de responsabilidad social y ambiental (campamentos forestales, infraestructura, instalaciones, etc.). Se mide en valores absolutos monetarios y en forma anual.

Indicador 50: Visitas a las reservas naturales: mide la cantidad de personas en forma semestral que visitan las reservas naturales del ente (en caso de que la sociedad posea en su patrimonio éstos espacios naturales) y como un indicador de compromiso con el medio y para ser reconocido como actor positivo de la sostenibilidad.

Indicador 51: Gestión de comunidades: se refiere al número de contactos en forma trimestral con terceros «críticos» a las actividades productivas de la empresa (vecinos, escuelas, comunidades, áreas rurales, etc.). El objetivo es lograr un relevamiento de problemas, analizar inconvenientes 
y realizar un diagnóstico de plan de acción, para solución de los mismos en las áreas de influencia y como una evidencia de la responsabilidad social de la empresa.

Indicador 52: Número de niños en programas de extensión ambiental: como complemento del anterior indicador, mide en forma semestral los planes de extensión ambiental a los niños de áreas rurales 0 escuelas vecinas a los predios forestales.

Indicador 53: $N^{\circ}$ de personas internas capacitadas en temas ambientales: mide en forma semestral la cantidad de capacitaciones realizadas a personal propio de la empresa y el avance de las mismas en relación con las capacitaciones programadas. Este indicador evidencia la responsabilidad ambiental de la empresa a través del involucramiento del personal propio en temas ambientales y sociales.

Indicador 54: $\mathrm{CO}_{2}$ capturado en el año: como parte de su ciclo vital, las plantaciones forestales utilizan la energía lumínica del sol para fotosintetizar carbohidratos a partir del dióxido de carbono y el agua, expulsando oxígeno como desecho de la reacción. Esta acción mejora el ambiente y genera satisfacción de necesidades básicas. Este indicador mide para los árboles y especies de la empresa forestal la absorción de dióxido de carbono, uno de los principales gases del efecto invernadero. De ahí la importancia por conocer en cada una de sus especies, cuánto captura y cuánto puede mantener capturado el bosque. La cantidad de C02 que un árbol captura se relaciona de manera directa con su tasa de crecimiento. Los árboles que más crecen son los que más carbono capturan en su madera (característica muy pronunciada en los eucaliptos que sumada a otras cualidades lo hacen atractivo para la reforestación). Este indicador se mide en toneladas capturadas por hectárea y por año.

Indicador 55: Auditorías captura de carbono: cantidad de mediciones anuales realizadas por asesores técnicos externos y empresas especializadas, para medir en forma anual el $\mathrm{CO}_{2}$ capturado de la atmósfera por las plantaciones forestales de la empresa.

Indicador 56: Accidentes fatales: indicador que muestra la cantidad de accidentes fatales a colaboradores directos 0 indirectos por las actividades productivas de la empresa (silvícolas, producción y cosecha forestal).

Indicador 57: Incidentes reportados: incidentes laborales reportados por los usuarios o las jefaturas (no accidentes) producidos por las actividades productivas de la empresa y que son reportados a través del sistema de seguimiento de incidentes. Esto permite actualizar la base de datos y resolverlos. De medición mensual.

Indicador 58: IFAT Índice de frecuencia de accidentes laborales: mide la frecuencia de los accidentes ocurridos, relacionando «Número de accidentes* 200 000/horas hombre», donde 200000 sería $100 \times 40$ horas semanales $\times 50$ semanas al año. De medición mensual.

Indicador 59: ISAT Índice de severidad de accidentes laborales: mide los días perdidos de trabajo en función de la severidad de los accidentes ocurridos. Relaciona para este indicador en valor absoluto los números de días perdidos por accidentes/horas hombre trabajadas* $200000(=100$ $x 40$ horas semanales $x 50$ semanas al año). De medición mensual.

Indicador 60: Ausentismo colaboradores directos: mide la ausencia de una persona de su puesto de trabajo, en horas que correspondan a un día laborable, dentro de la jornada legal de trabajo, lo que ocasiona costos laborales incrementales. Este indicador también está relacionado con la responsabilidad social de la empresa. Mide en porcentaje y en forma mensual las horas de ausentismo totales del mes versus las horas totales trabajadas.

Por último los indicadores apropiados para medir el grado de cumplimiento de los objetivos en la dimensión aprendizaje y crecimiento serían los siguientes (Tabla 5): 
Tabla 5. Propuesta de indicadores estratégico para la dimensión aprendizaje y crecimiento (empresa forestal)

\begin{tabular}{|c|c|c|c|c|c|c|c|}
\hline $\begin{array}{l}\# \\
\mathrm{OE}\end{array}$ & $\begin{array}{l}\text { NOMBRE OBJETIVO } \\
\text { ESTRATÉGICO }\end{array}$ & $\begin{array}{l}\# \\
\text { IND }\end{array}$ & NOMBRE INDICADOR & $\begin{array}{l}\text { UNIDAD DE } \\
\text { MEDIDA }\end{array}$ & $\begin{array}{l}\text { FREC. } \\
\text { MED. }\end{array}$ & $\begin{array}{l}\text { REAL } \\
\text { MENSUAL }\end{array}$ & $\begin{array}{l}\text { PLAN } \\
\text { MENSUAL }\end{array}$ \\
\hline & \multicolumn{7}{|c|}{ DIMENSIÓN APRENDIZAJE Y CRECIMIENTO } \\
\hline \multirow[t]{5}{*}{ OE15 } & \multirow{3}{*}{$\begin{array}{l}\text { Fortalecer la } \\
\text { organización forestal } \\
\text { y retener talentos }\end{array}$} & 61 & Retención de colaboradores de alto desempeño & $\%$ & Mensual & & \\
\hline & & 62 & \% Cargos Críticos con Sucesores Preparados & $\%$ & Mensual & & \\
\hline & & 63 & Cantidad de evaluaciones de desempeño & $\%$ & Mensual & & \\
\hline & \multirow{2}{*}{$\begin{array}{l}\text { asegurando } \\
\text { continuidad }\end{array}$} & 64 & Engagement personal directo & $\%$ & Mensual & & \\
\hline & & 65 & Rotación del personal & $\%$ & Mensual & & \\
\hline \multirow[t]{2}{*}{$0 \mathrm{E} 16$} & \multirow{2}{*}{$\begin{array}{l}\text { Promover conoci- } \\
\text { miento de la empresa } \\
\text { forestal y su entorno } \\
\text { mediante }\end{array}$} & 66 & $N^{\circ}$ capacitaciones & $\begin{array}{l}N^{0} \text { de capa- } \\
\text { citaciones }\end{array}$ & Mensual & & \\
\hline & & 67 & $\mathrm{~N}^{\circ}$ personas a capacitar & $\begin{array}{l}\mathrm{N}^{0} \text { personas } \\
\text { a capacitar }\end{array}$ & Mensual & & \\
\hline 0E17 & $\begin{array}{l}\text { Establecer relación } \\
\text { con contratistas a } \\
\text { mediano plazo }\end{array}$ & 68 & $\begin{array}{l}\text { Porcentaje de volumen de producción } \\
\text { bajo contrato de mediano plazo }\end{array}$ & $\%$ & Trimestral & & \\
\hline
\end{tabular}

Fuente: Elaboración propia

Indicador 61: Retención de colaboradores de alto desempeño: muestra la efectividad de la organización de recursos humanos de la sociedad para mantener la continuidad de las operaciones, ya que mide aquellos colaboradores de alto desempeño que fueron retenidos por la sociedad.

Indicador 62: Porcentaje de cargos críticos con sucesores preparados: mide la efectividad del plan de sucesión de la sociedad, ya que se evalúa que cantidad de cargos críticos tiene definida la sociedad dentro del plan de sucesión. De medición anual.

Indicador 63: Evaluaciones de desempeño: representa otro indicador clave para medir la continuidad del plantel de colaboradores mediante las evaluaciones de desempeño de los mismos. Mide en porcentaje la cantidad de colaboradores directos que han pasado por el sistema de gestión de desempeño de la sociedad sobre el total de colaboradores de la sociedad. De medición anual.

Indicador 64: Engagement: mide el grado de compromiso que tienen los colaboradores directos con la empresa y cuánto demuestra el empleado que está implicado y entusiasmado con su trabajo. Se mide en porcentaje a partir de un relevamiento $y$ encuesta que se puede realizar a los colaboradores directos. De medición anual.

Indicador 65: Rotación del personal: muestra el grado de permanencia del personal propio en la empresa, lo que demuestra su grado de compromiso y engagement con la misma. Se mide en porcentaje de personal que se desvinculó en el año en función de la dotación total de la misma.

Indicador 66: $N^{\circ}$ de capacitaciones: de medición semestral muestra el grado de capacitación que tienen los colaboradores propios respecto del plan de capacitación prefijado.

Indicador 67: $N^{\circ}$ de personas a capacitar: de medición semestral muestra las capacitaciones a encarar en el ejercicio del personal propio en las distintas áreas. Indicador 68: Porcentaje de volumen de producción bajo contrato de mediano plazo: mide el aseguramiento de los contratistas de producción con contratos de volumen de cosecha de madera a entregar y ya comprometidos con clientes. Asegura el crecimiento y aseguramiento de la producción a través de contratos formales.

A continuación, en Tabla 6 , se presenta un resumen gráfico de panel de control de indicadores estratégicos específicos para la industria. 
Tabla 6. Modelo final de panel de control de indicadores estratégico (empresa forestal)

\begin{tabular}{|c|c|c|c|c|c|c|c|}
\hline $\begin{array}{l}\# \\
\mathrm{OE}\end{array}$ & $\begin{array}{l}\text { NOMBRE OBJETIVO } \\
\text { ESTRATÉGICO }\end{array}$ & $\begin{array}{l}\text { \# } \\
\text { IND }\end{array}$ & NOMBRE INDICADOR & $\begin{array}{l}\text { UNIDAD DE } \\
\text { MEDIDA }\end{array}$ & $\begin{array}{l}\text { FREC. } \\
\text { MED. }\end{array}$ & $\begin{array}{l}\text { REAL } \\
\text { MENSUAL }\end{array}$ & $\begin{array}{l}\text { PLAN } \\
\text { MENSUAL }\end{array}$ \\
\hline & \multicolumn{7}{|l|}{ DIMENSIÓN FINANCIERA } \\
\hline 0E01 & $\begin{array}{l}\text { Incrementar y poten- } \\
\text { ciar la valorización } \\
\text { de bosques propios }\end{array}$ & 1 & $\begin{array}{l}\text { Tasación forestal mediante flujos descon- } \\
\text { tados }\end{array}$ & MUSD & Anual & & \\
\hline \multirow[t]{7}{*}{ OE02 } & Optimizar margen & 2 & Margen total excluido costo de madera en pie & MUSD & Mensual & & \\
\hline & bruto de ventas & 3 & Margen neto pie eucaliptus aserrable (total) & USD $/ \mathrm{m}^{3}$ & Mensual & & \\
\hline & excluido el costo de & 4 & Margen neto pie eucaliptus pulpable (total) & $\mathrm{USD} / \mathrm{m}^{3}$ & Mensual & & \\
\hline & madera en pie & 5 & EBITDA Forestal & MUSD & Mensual & & \\
\hline & & 6 & EBITDA / (KT + Activo Fijo Neto) & $\%$ & Trimestral & & \\
\hline & & 7 & Rotación del KT (KT Forestal / Ventas) & $\%$ & Mensual & & \\
\hline & \multicolumn{7}{|l|}{ DIMENSIÓN CLIENTES } \\
\hline 0E03 & $\begin{array}{l}\text { Cumplir programa de } \\
\text { venta a terceros }\end{array}$ & 8 & Volumen de venta a terceros & $\mathrm{m}^{3}$ & Mensual & & \\
\hline \multirow[t]{7}{*}{ OEO4 } & \multirow{6}{*}{$\begin{array}{l}\text { Cumplir oferta } \\
\text { producto/calidad en } \\
\text { el corto } \\
\text { y largo plazo }\end{array}$} & 9 & Volumen de venta total & $\mathrm{m}^{3}$ & Mensual & & \\
\hline & & 10 & Volumen de venta en pie & $\mathrm{m}^{3}$ & Mensual & & \\
\hline & & 11 & Volumen pulpable / Volumen Total & $\%$ & Mensual & & \\
\hline & & 12 & Volumen aserrable / Volumen total & $\%$ & Mensual & & \\
\hline & & 13 & Volumen podado / Volumen total & $\%$ & Mensual & & \\
\hline & & 14 & Volumen de venta inter-compañía & $\mathrm{m}^{3}$ & Mensual & & \\
\hline & DIMENSIÓN PROCESO DE P & PATRIM & MONIO FORESTAL, PROCESOS Y TECNOLOGÍA & & & & \\
\hline OE05 & Optimizar costos & & 15 Costos de producción unitarios & $\mathrm{USD} / \mathrm{m}^{3}$ & Mensual & & \\
\hline & y gastos & & 16 Costos directos silvícolas & MUS\$ & Trimestral & & \\
\hline & & & 17 Costos de reforestación & USD/Ha. & Anual & & \\
\hline & & & 18 Costo de plantación & USD/Ha. & Anual & & \\
\hline & & & 19 Costo de poda & USD/Ha. & Mensual & & \\
\hline & & & 20 Costo de raleo desecho & USD/Ha. & Mensual & & \\
\hline 0E06 & Cumplir plan silvícola & & 21 Superficie cosechada total & Has. & mensual & & \\
\hline & y de cosecha & & 22 Cumplimiento plan silvícola en sup. (Has) & Has. & Trimestral & & \\
\hline & & & 23 Cumplimieto plan silvicola en valores & MUSD & Trimestral & & \\
\hline & & & $24 \quad N^{\circ}$ de plantas de replante/ $^{\circ}$ de plantas totales & es $\%$ & Anual & & \\
\hline & & & 25 Superficie de plantación & Has. & Mensual & & \\
\hline & & & 26 Superficie de poda & Has. & Mensual & & \\
\hline & & & 27 Superficie de raleo desecho & Has. & Mensual & & \\
\hline & & & $\begin{array}{l}28 \text { Cumplimiento planificación de manejo } \\
\text { trimestral (poda-raleo) }\end{array}$ & $\%$ & Trimestral & & \\
\hline
\end{tabular}

[Continúa pág. sgte.] 


\begin{tabular}{|c|c|c|c|c|c|c|c|}
\hline $\begin{array}{l}\# \\
\mathrm{OE} \\
\end{array}$ & $\begin{array}{l}\text { NOMBRE OBJETIVO } \\
\text { ESTRATÉGICO }\end{array}$ & $\begin{array}{l}\# \\
\text { IND } \\
\end{array}$ & NOMBRE INDICADOR & $\begin{array}{l}\text { UNIDAD DE } \\
\text { MEDIDA }\end{array}$ & $\begin{array}{l}\text { FREC. } \\
\text { MED. }\end{array}$ & $\begin{array}{l}\text { REAL } \\
\text { MENSUAL }\end{array}$ & $\begin{array}{l}\text { PLAN } \\
\text { MENSUAL }\end{array}$ \\
\hline & \multicolumn{7}{|c|}{ DIMENSIÓN PROCESO DE PATRIMONIO FORESTAL, PROCESOS Y TECNOLOGÍA } \\
\hline OE06 & $\begin{array}{l}\text { Cumplir plan silví- } \\
\text { cola y de cosecha } \\
\text { [Cont.] }\end{array}$ & 29 & $\begin{array}{l}\text { Evolución productividad potencial } \\
\text { de plantaciones }\end{array}$ & $\mathrm{m}^{3} /$ ha./año & Anual & & \\
\hline \multirow[t]{2}{*}{ OE07 } & \multirow{2}{*}{$\begin{array}{l}\text { Mecanizar proce- } \\
\text { sos operativos de } \\
\text { producción }\end{array}$} & 30 & Productividad por operario forestal & $\begin{array}{l}\mathrm{m}^{3} / \text { hombre/ } \\
\text { mes }\end{array}$ & mensual & & \\
\hline & & 31 & $\begin{array}{l}\text { Volumen de cosecha y raleo mecanizado / } \\
\text { Volumen Total }\end{array}$ & $\%$ & mensual & & \\
\hline \multirow[t]{7}{*}{ OEO8 } & \multirow{7}{*}{$\begin{array}{l}\text { Optimizar inver- } \\
\text { siones en Patrimo- } \\
\text { nio Forestal }\end{array}$} & 32 & Gastos Indirectos en Patrimonio Forestal & MUSD & Mensual & & \\
\hline & & 33 & $\begin{array}{l}\text { Programa de inversiones en Patrimonio } \\
\text { Forestal }\end{array}$ & MUSD & Trimestral & & \\
\hline & & 34 & Disposición de residuos & Has. & Mensual & & \\
\hline & & 35 & Costo en taipas & Has. & Mensual & & \\
\hline & & 36 & Herbicida preplantacion & Has. & Mensual & & \\
\hline & & 37 & Costo en rastra / rome & Has. & Mensual & & \\
\hline & & 38 & Cultivo quimico preplantacion & Has. & Mensual & & \\
\hline \multirow[t]{2}{*}{ OEO9 } & $\begin{array}{l}\text { Gestionar recursos } \\
\text { para crec. forestal }\end{array}$ & 39 & Otras hectáreas compradas & Has. & Trimestral & & \\
\hline & \multicolumn{7}{|c|}{ DIMENSIÓN RESPONSABILIDAD SOCIAL Y AMBIENTAL } \\
\hline \multirow[t]{7}{*}{ OE10 } & \multirow{7}{*}{$\begin{array}{l}\text { Mantener } \\
\text { biodiversidad }\end{array}$} & 40 & Cumplimiento de vbles. biodiversidad de FSC & $\%$ & Anual & & \\
\hline & & $\underline{41}$ & Consumo de agroquímicos por ha. plantada & Its. / ha. & Anual & & \\
\hline & & 42 & $\mathrm{~N}^{\circ}$ cursos de agua monitoreados en calidad & $\begin{array}{l}\mathrm{n}^{0} \text { de cursos } \\
\text { de agua }\end{array}$ & Semestral & & \\
\hline & & 43 & Hectáreas de Reservas Naturales & Has. & Anual & & \\
\hline & & 44 & Has. de Reservas Naturales restauradas & Has. & Anual & & \\
\hline & & 45 & Certificación FSC & Hito & Anual & & \\
\hline & & 46 & $\begin{array}{l}\text { Hectáreas no quemadas de bosque nativo / } \\
\text { áreas de conservación }\end{array}$ & $\%$ & Semestral & & \\
\hline \multirow[t]{3}{*}{ OE11 } & Optimizar & 47 & Gastos Indirectos Administración RSA & MUSD & Mensual & & \\
\hline & inversiones & 48 & Gastos Indirectos Gestión Ambiental y Social & MUSD & Mensual & & \\
\hline & en RSA & 49 & Programa de inversiones RSA & MUSD & Anual & & \\
\hline \multirow[t]{4}{*}{ OE12 } & \multirow{4}{*}{$\begin{array}{l}\text { Ser reconocido } \\
\text { como actor } \\
\text { positivo en } \\
\text { la comunidad }\end{array}$} & 50 & Visitas a las Reservas Naturales & $\begin{array}{l}\text { Cantidad de } \\
\text { visitantes }\end{array}$ & Semestral & & \\
\hline & & 51 & Gestión de comunidades & $\begin{array}{l}\text { Cant. de } \\
\text { terceros } \\
\text { gestionados }\end{array}$ & Trimestral & & \\
\hline & & 52 & $\mathrm{~N}^{0}$ de niños en prog, de extension ambiental & $\begin{array}{l}\text { Cantidad } \\
\text { de niños }\end{array}$ & Semestral & & \\
\hline & & 53 & $\begin{array}{l}\mathrm{N}^{\circ} \text { de personas internas capacitadas } \\
\text { en temas ambientales }\end{array}$ & $\begin{array}{l}\text { Cant. de } \\
\text { personas }\end{array}$ & Semestral & & \\
\hline
\end{tabular}

[Continúa pág. sote.] 


\begin{tabular}{|c|c|c|c|c|c|c|c|}
\hline \multirow[t]{2}{*}{$\begin{array}{l}\# \\
0 \mathrm{E} \\
\end{array}$} & $\begin{array}{l}\text { NOMBRE OBJETIVO } \\
\text { ESTRATÉEICO }\end{array}$ & $\begin{array}{l}\# \\
\text { IND } \\
\end{array}$ & NOMBRE INDICADOR & $\begin{array}{l}\text { UNIDAD DE } \\
\text { MEDIDA }\end{array}$ & $\begin{array}{l}\text { FREC. } \\
\text { MED. }\end{array}$ & $\begin{array}{l}\text { REAL } \\
\text { MENSUAL }\end{array}$ & $\begin{array}{l}\text { PLAN } \\
\text { MENSUAL }\end{array}$ \\
\hline & \multicolumn{7}{|c|}{ DIMENSIÓN PROCESO DE PATRIMONIO FORESTAL, PROCESOS Y TECNOLOGÍA } \\
\hline \multirow[t]{2}{*}{$0 \mathrm{E} 13$} & Maximizar captura & 54 & $\mathrm{CO}_{2}$ capturado en el año & Ton. & Anual & & \\
\hline & $\begin{array}{l}\text { de } \mathrm{CO}_{2} \text { en bosques } \\
\text { propios }\end{array}$ & 55 & Auditorías captura de carbono & $\begin{array}{l}\text { Cant. de } \\
\text { auditorías }\end{array}$ & Anual & & \\
\hline \multirow[t]{6}{*}{ OE14 } & \multirow[t]{5}{*}{$\begin{array}{l}\text { Minimizar } \\
\text { Accidentes } \\
\text { Forestales }\end{array}$} & 56 & Accidentes fatales & $\begin{array}{l}\text { Cant. de } \\
\text { accidentes } \\
\text { fatales }\end{array}$ & Mensual & & \\
\hline & & 57 & Incidentes reportados & $\begin{array}{l}\text { Cant. de } \\
\text { incidentes } \\
\text { reportados }\end{array}$ & Mensual & & \\
\hline & & 58 & IFAT Indice frecuencia de accidentes forestales & Indicador & Mensual & & \\
\hline & & 59 & ISAT Indice de severidad de accid. forestales & Indicador & Mensual & & \\
\hline & & 60 & Ausentismo colaboradores directos & $\%$ & Mensual & & \\
\hline & \multicolumn{7}{|c|}{ DIMENSIÓN APRENDIZAJE Y CRECIMIENTO } \\
\hline \multirow[t]{5}{*}{ OE15 } & \multirow{5}{*}{$\begin{array}{l}\text { Fortalecer la orga- } \\
\text { nización forestal } \\
\text { y retener talentos } \\
\text { asegurando } \\
\text { continuidad }\end{array}$} & 61 & Retención de colaboradores de alto desempeño & $\%$ & Mensual & & \\
\hline & & 62 & \% Cargos Críticos con Sucesores Preparados & $\%$ & Mensual & & \\
\hline & & 63 & Cantidad de evaluaciones de desempeño & $\%$ & Mensual & & \\
\hline & & 64 & Engagement personal directo & $\%$ & Mensual & & \\
\hline & & 65 & Rotación del personal & $\%$ & Mensual & & \\
\hline \multirow[t]{2}{*}{ OE16 } & $\begin{array}{l}\text { Promover } \\
\text { conocimiento de la }\end{array}$ & 66 & $\mathrm{~N}^{\circ}$ capacitaciones & $\begin{array}{l}N^{0} \text { de capaci- } \\
\text { taciones }\end{array}$ & Mensual & & \\
\hline & $\begin{array}{l}\text { empresa forestal } \\
\text { y su entorno } \\
\text { mediante }\end{array}$ & 67 & $\mathrm{~N}^{\circ}$ personas a capacitar & $\begin{array}{l}\mathrm{N}^{0} \text { personas a } \\
\text { capacitar }\end{array}$ & Mensual & & \\
\hline OE17 & $\begin{array}{l}\text { Establecer } \\
\text { relación con } \\
\text { contratistas a } \\
\text { mediano plazo }\end{array}$ & 68 & $\begin{array}{l}\text { Porcentaje de volumen de producción } \\
\text { bajo contrato de mediano plazo }\end{array}$ & $\%$ & Trimestral & & \\
\hline
\end{tabular}

Fuente: Elaboración propia

\section{Algunas conclusiones}

La propuesta que se presenta en el artículo representa una efectiva herramienta de control de gestión y control, ya que a través del diseño de un sistema de información integrado de datos (panel de control, reportes e indicadores de gestión) brinda información cuantitativa y cualitativa de la evolución del ciclo vital de las plantaciones y sobre aspectos integrales de la marcha del negocio: financieros, comerciales, producción y tecnología, ambientales y sociales. Esto permitirá la toma de decisiones estratégicas a los usuarios internos del ente y el monitoreo del cumplimiento de la visión y misión del ente 0 meta de triple resultado (económico-financiero, social y ambiental).

Las conclusiones principales alcanzadas en el trabajo son las siguientes:

- Los bosques cultivados son activos biológicos donde los efectos de su medición y revelación, 
así como su administración, registración, gestión, control e información contable, tienen un vector transversal a todos los segmentos contables.

- La información generada por el segmento de Contabilidad de Gestión a lo largo del ciclo vital resulta trascendente, al tratarse de procesos de producción continuos y terminales, de un largo período de extensión.

- El concepto de «producción» que caracteriza a los activos forestales se aproxima más a un concepto económico de beneficio y, en consecuencia, la Contabilidad de Gestión (en contraposición con la Contabilidad Patrimonial) resulta de suma utilidad para generar informes más aptos para el control empresarial.
- Las decisiones que toman los administradores de un ente forestal, a través de la información disponible y el uso de las mejores técnicas silviculturales, influyen en el control de costos y gestión que los involucran. Por lo tanto, deben nutrirse de información de gestión en cantidad y calidad necesaria, relativa a la operatoria de los bosques cultivados a efectos de monitorear y controlar su gestión.

- El éxito del proceso de planeamiento estratégico en entes forestales se verá reflejado al final del ciclo biológico, con el alcance 0 no del logro de incrementar y potenciar la rentabilidad de los bosques dentro de la meta de triple resultado: crear valor económico en forma sostenible, con creación de valor social y ambiental.

\section{Referencias bibliográficas}

- Espinoza, R. (2012). Marketing y Ventas (web log post). Recuperado en Diciembre 2015 de: http:// robertoespinosa.es/2012/10/14/ como-definir-mision-vision-y-valores-en-la-empresa/

- García Casella, C.L. (2000, junio). Fundamentación científica de la relación entre modelos y sistemas contables. Contabilidad y Auditoría, 6(11), 1-12. Recuperado en Diciembre 2015 de: https://ojs.econ.uba. ar/ojs/index.php/Contyaudit/article/ view/193.

- Mancini, A.A (2013, junio). Activos Biológicos Forestales: análisis comparativo entre valor razonable y costo histórico, en cuanto a su valuación, gestión y control. Enfoques de Contabilidad y Auditoría, (6), 26-32.

- Ministerio de Economía y Servicios Públicos, Secretaría de Agricultura, Ganadería y Pesca (1995). Manual para productores de eucaliptus de la Mesopotamia Argentina. Concordia, Entre Ríos, Argentina: Grupo Forestal, EEA, INTA. Recuperado en Diciembre 2015 de http://inta.gob. ar/sites/default/files/script-tmpmanual_para_productores_de_eucaliptos_de_la_mesopotam.pdf - Soto, E.M. (2011). Introducción al pensamiento contable de García Casella. Armenia-Quindío, Colombia: Optigtraf. Recuperado de: http:// www.eutimiomejia.com/textos/pdf/ LIBRO INTRODUCCION PENSAMIENTO CONTABLE.pdf

- Rudi, E. (2005). La Resolución Técnica 22: Actividad agropecuaria y la Contabilidad de Gestión. XXVIII Congreso Argentino de Profesores Universitarios de Costos, (2), 288-304. Mendoza, Argentina. Recuperado de: http://eco.unne.edu.ar/contabilidad/ costos/XXVlilapuco/tomo\%202.1.pdf.
- Torres, C. (2010). Normas Contables para la Actividad Agropecuaria, Resolución Técnica N 22-NIC No 41-NIIF para Pymes sección 34 (2da. Edición). Buenos Aires, Argentina: Osmar D. Buyatti.
Registro bibliográfico
Mancini, A.A. (2016). Herramientas de contabilidad de gestión para generar valor económico, ambiental y social en activos biológicos forestales. Panel de control e indicadores estratégicos en silvicultura. Revista Ciencias Económicas, 13(02), 49-72. 